\title{
Clinical Commentary
}

\section{Gender and Chronic Obstructive Pulmonary Disease Why It Matters}

\author{
MeiLan K. Han ${ }^{1}$, Dirkje Postma², David M. Mannino³, Nicholas D. Giardino', Sonia Buist ${ }^{4}$, Jeffrey L. Curtis ${ }^{1,5}$, and \\ Fernando J. Martinez ${ }^{1}$ \\ ${ }^{1}$ Division of Pulmonary and Critical Care Medicine, University of Michigan Health System, Ann Arbor, Michigan; ${ }^{2}$ University Medical Center \\ Groningen, Groningen, The Netherlands; ${ }^{3}$ Division of Pulmonary and Critical Care Medicine, University of Kentucky, Lexington, Kentucky; ${ }^{4}$ Division \\ of Pulmonary and Critical Care Medicine, Oregon Health and Sciences University, Portland, Oregon; and ${ }^{5}$ Pulmonary and Critical Care Section, \\ Veterans Affairs Health System, Ann Arbor, Michigan
}

\begin{abstract}
The prevalence of chronic obstructive pulmonary disease (COPD) in women is increasing, as is hospitalization for COPD. The number of women dying of COPD in the United States now surpasses men. Despite this, research suggests that physicians are still more likely to correctly diagnose men with COPD than women. Increased tobacco use in women likely explains some of the increase in the prevalence of COPD in women, but data suggest that women may actually be at greater risk of smoking-induced lung function impairment, more severe dyspnea, and poorer health status for the same level of tobacco exposure. The degree to which these observations represent biologic, physiologic, or sociologic differences is not known. Nonsmokers with COPD are also more likely to be female. In addition, new evidence is emerging that men and women may be phenotypically different in their response to tobacco smoke, with men being more prone to an emphysematous phenotype and women an airway predominant phenotype. Inasmuch as COPD is a disease of inflammation, it is also possible that sexual dimorphism of the human immune response may also be responsible for gender differences in the disease. More data are still needed on what the implications of these findings are on therapy. In this clinical commentary, we present current knowledge regarding how gender influences the epidemiology, diagnosis, and presentation of COPD in addition to physiologic and psychologic impairments and we attempt to offer insight into why these differences might exist and how this may influence therapeutic management.
\end{abstract}

Keywords: tobacco susceptibility; smoking; sex; obstructive lung disease

The prevalence, morbidity, and mortality of chronic obstructive pulmonary disease (COPD) in women are increasing in the United States. In 2000, for the first time, the number of women dying of COPD in the United States surpassed the number of men (1). Questions have been raised regarding how gender affects susceptibility to tobacco smoke. Even more interesting is the possibility that the nature of biologic injury may differ

(Received in original form April 9, 2007; accepted in final form August 2, 2007) Supported by NIH/NHLBI 2K24 HL004212, U10 HL074422, and RO1 HL082480 from the USPHS; and by Merit Review funding and a REAP grant from the Biomedical and Laboratory Research and Development Service, Department of Veterans Affairs.

Correspondence and requests for reprints should be addressed to Fernando J. Martinez, M.D., M.S., 1500 East Medical Center Drive, 3916 Taubman Center, Ann Arbor, MI 48109-0360. E-mail: fmartine@umich.edu

This article has an online supplement, which is accessible from this issue's table of contents at www.atsjournals.org

Am J Respir Crit Care Med Vol 176. pp 1179-1184, 2007

Originally Published in Press as DOI: 10.1164/rccm.200704-553CC on August 2, 2007

Internet address: www.atsjournals.org between men and women. Women with COPD also report more dyspnea and lower self-reported health status compared with men after adjusting for smoking burden and lung function (2). Whether these differences reflect physiologic differences or comorbidities such as anxiety is unknown. In this clinical commentary, we present current knowledge regarding how gender influences the diagnosis, physiology, and presentation of COPD, and integrate this information to develop hypotheses as to why these differences might exist to identify areas for future research. Throughout this article, we will primarily use the term "gender." The terms "gender" and "sex" have been used interchangeably. "Sex" has more frequently been used in reference to characteristics accorded to biologic differences, such as sex chromosomes and hormones. In this article, we will use "gender" to acknowledge the complex interactions between biologic, psychologic, and sociologic factors that make men and women different.

\section{EPIDEMIOLOGY}

COPD is the fourth leading cause of death in the United States (3). The biggest risk factor for disease development (in the developed world) is tobacco smoke. For women in the developing world, where fuels such as coal and biomass are used for indoor cooking and heating, several studies have reported an association between exposure to biomass smoke and COPD (4). Significant methodologic differences exist in COPD prevalence estimates, accounting for a large amount of variability in the available data. From a global perspective, a meta-analysis of 62 population-based studies on prevalence for COPD published between 1990 and 2004 reported a pooled prevalence for COPD at $9.8 \%$ among men and $5.6 \%$ among women (5). A very well done study in five Latin American cities using probability sampling and confirmation with spirometric testing also reported that the age-adjusted prevalence was higher for men than women in every city sampled, ranging from $11.4 \%$ of men to $7.5 \%$ of women in Mexico City, to $23 \%$ of men and $11.6 \%$ of women in Montevideo (6). However, the most recent survey from an economically advanced country, Austria, using carefully standardized methods identical to the methods used in the Latin American surveys, found an equal prevalence of COPD in men and women, and equal tobacco use (7). This study suggests that COPD prevalence in women is likely to increase markedly as women in all countries adopt the same lifestyle habits as men, and are exposed to the same workplace risks.

In the United States, prevalence data exist both from the National Health Interview Survey (NHIS) and the National Health and Nutrition Examination Survey (NHANES). The NHIS data from 2003 cited higher rates of combined chronic 
bronchitis and emphysema in women than in men, 7.2 versus 4.4 million cases (8). NHANES data are based on population screening and spirometric confirmation; NHANES reported 74.3 cases per 1,000 men versus 58.2 cases per 1,000 women for moderate obstructive lung disease and 90.9 cases per 1,000 men versus 48.7 cases per 1,000 women for mild obstructive lung disease, a total of 13.6 versus 10.6 million cases for men and women, respectively (1). Both the NHIS and NHANES data have their inherent biases, and it is worth emphasizing that the NHIS data are based entirely on self-report. From a sociologic standpoint, women consistently are more likely to report symptoms, give poorer self-evaluation of health, and have more chronic conditions, which may bias the NHIS data toward increased prevalence of disease in women (9). NHIS data from 2003 reported the age-adjusted prevalence of chronic bronchitis to be 26.8 cases per 1,000 individuals in men and 52.6 cases per 1,000 in women, and emphysema at 16.6 cases per 1,000 individuals in men and 12.8 cases per 1,000 individuals in women (8). The increased prevalence of chronic bronchitis in women raises an important question of whether men and women are phenotypically different in their susceptibility to tobacco smoke.

More women are also being hospitalized for COPD. In the United States, hospitalization rates for men were greater than those for women through the 1980s, although since 1995, unadjusted rates have been similar (1). Canada has also reported increase in hospitalizations for women, particularly in older age categories (10). One explanation might be that women live longer, and thus are at risk for hospitalization longer. Other possible explanations include gender-related physiologic differences that affect prognosis, or differences in highly correlated comorbidities such as cardiovascular disease or anxiety and depression, which might lead to increased frequency of hospitalization.

Mortality for women with COPD in the United States is also increasing. Between 1980 and 2000, mortality rates for COPD among men increased by $13 \%$ and have remained steady since 1985 (1). In women, however, between 1980 and 2000, death rates almost tripled, and in 2000 for the first time in terms of absolute numbers, more women than men died of COPD (1). Data from Canada also suggest increasing mortality for women with COPD (11). The increase in COPD mortality for women is likely due, in part, to the tobacco epidemic in women. It remains unclear, however, if biologic differences between men and women impact increasing mortality. Higher absolute mortality for COPD in women may be biased by the differential presence of comorbidities, such as depression or body mass depletion. In addition, as women in general live longer, they may be living long enough to die of COPD as opposed to dying earlier of other diseases.

\section{GENDER BIAS IN DIAGNOSIS OF DISEASE}

Accumulating evidence suggests that physicians show bias against diagnosing COPD in women. A 2001 study that sampled 200 primary care physicians in North America presented two hypothetical cases of cough and dyspnea in smokers, one male and the other female (12). Physicians were then asked for provisional diagnosis and initial diagnostic steps. COPD was given as the most probable diagnosis significantly more often for the male case scenario than for the female case scenario (64.6 vs. $49 \%)$. When spirometric data were provided, the difference in rate of COPD diagnosis between the sexes narrowed (76\% for the man vs. $64.6 \%$ for the woman). In a more recent similar study conducted in Spain, COPD was also more likely to be the primary diagnosis for men than for women (odds ratio [OR], 1.55; 95\% confidence interval [CI], 1.15-2.1) (13). Interestingly, this gender bias disappeared after physicians were shown the abnormal results of spirometry, which emphasizes the importance of ordering spirometry. Because other reports suggest that primary care physicians underutilize spirometry (14), and women are also less likely to receive specialty referrals than men (15), one may conclude that women may be receiving spirometry less often. This concern was validated by the Confronting COPD Survey (16), which found, after adjusting for age, pack-years, country, and dyspnea scores, that women were less likely to have had spirometry (OR, 0.84; 95\% CI, 0.72-0.98) but more likely to have had smoking cessation advice (OR, 1.57; 95\% CI, 1.33-1.86). Together, these data suggest that women with COPD may be less likely to be diagnosed and consequently less likely to be treated for their COPD.

\section{TOBACCO SUSCEPTIBILITY}

Although increased tobacco use will contribute to the increasing prevalence of women with COPD, it has been hypothesized that women may be at greater risk of smoking-induced lung function impairment for the same level of tobacco exposure (17). Multiple studies have attempted to address this question in one form or another. A list of studies with varying study design appears in Table E1 of the online supplement. One of the earliest and largest studies was the British Physicians Study, which tracked thousands of physicians and the impact of behaviors such as smoking (18, 19). Mortality rates from emphysema and bronchitis were similar between male and female smokers, and risk of COPD development correlated with the amount of tobacco consumed, but not with gender. Most studies, however, have reported greater loss of lung function in women than men. A systematic review and metaanalysis of studies examining longitudinal loss of lung function concluded that female current smokers had a significantly faster annual decline in $\mathrm{FEV}_{1} \%$ predicted with increasing age than their male counterparts (Table E2) (20).

Interestingly, analysis of data from the Euroscop study demonstrated that women with COPD and an $\mathrm{FEV}_{1} / \mathrm{FVC}$ ratio of less than the median lost lung function at a rate of $32 \mathrm{ml}$ per year faster than women with less obstruction, which was a much larger difference than in men $(8 \mathrm{ml} / \mathrm{yr})$. They also reported that, in those with moderate airflow limitation, an increase in the number of cigarettes smoked caused a steeper annual decline in $\mathrm{FEV}_{1}$ in men $(17 \mathrm{ml} / \mathrm{yr})$, without significant effect in women (21). The Lung Health Study reported that pulmonary function improved more with smoking cessation in women than in men $\left(\Delta \mathrm{FEV}_{1}, 3.7\right.$ vs. $\left.1.6 \% ; P<0.001\right)(22)$. These data suggest the rate of change in lung function over time may differ by gender.

If women are more susceptible to the effects of tobacco smoke, then the next logical question is Why? A study of 84 early-onset COPD families found a very high prevalence $(71.4 \%)$ of affected women (23). Further analysis of first-degree relatives of probands who were also current or ex-smokers showed that female first-degree relatives had significantly greater bronchodilator responsiveness and greater risk of reduced $\mathrm{FEV}_{1}$ than their male first-degree relatives. These differences were only seen among current or ex-smokers, implying a genetic predisposition for smoking-related lung damage that is gender specific.

Other explanations for differences in reported tobacco susceptibility include speculations that women may underreport tobacco consumption. However, a meta-analysis of 26 validation studies found self-reported smoking data to be generally accurate (24). Another explanation for a gender difference in tobacco susceptibility may simply be a dose-dependent effect. The airways of women are smaller and thus each cigarette represents a proportionately greater exposure. Secondhand smoke exposure and differences in cigarette brand preferences could also play a role. Other hypotheses vary from hormonal effects on lung 
development and airway size, through heightened sensitivity of $\beta$ - and acetylcholine receptors and increased cadmium absorption from cigarette smoke in women, due to increased heavy metal absorption associated with menstruation-induced anemia $(25,26)$, to differences in cigarette smoke metabolism (27).

\section{GENDER DIFFERENCES IN COPD: SYMPTOMS AND QUALITY OF LIFE}

The physiologic changes of COPD affect women and men differently in terms of symptoms and quality of life. In the Confronting COPD International Survey, women were more likely to report severe dyspnea (OR, 1.30; 95\% CI, 1.10-1.54) despite significantly fewer pack-years of smoking, while reporting similar degrees of cough (OR, 84; 95\% CI, 0.72-0.98) and less sputum (OR, 0.84; 95\% CI, 0.72-0.98) (16). More recently, in a prospective study of symptoms in male and female patients with mild to moderate COPD, similar proportions of men and women reported symptoms despite significantly greater pack-years of smoking in men (21). Level of $\mathrm{FEV}_{1}$ as well as its improvement and deterioration over time correlated more closely, respectively, with prevalence, remission, and incidence of symptoms in male patients with COPD, indicating that, particularly in males, the presence of symptoms is a good predictor of disease status and/or underlying disease activity (21).

Men and women with COPD may also differ in the intensity of symptoms and health-related quality of life associated with their disease. In a recent case series of $53 \mathrm{FEV}_{1}$-matched men and women with COPD, women were significantly younger and smoked less, yet reported greater dyspnea as measured by the Modified Medical Research Council scale (28). In a separate series of $146 \mathrm{FEV}_{1}$-matched men and women with $\mathrm{COPD}$, the same authors reported that, compared with men, women also had worse scores in all domains of the St. George's Respiratory Questionnaire (SGRQ) (29). Thus, for a similar degree of physiologic impairment, women experienced more severe dyspnea and worse health status. Furthermore, the factors that determine health-related quality of life for men and women with COPD may differ by gender. Multiple linear regression analysis showed that, in men, total SGRQ score was predicted by dyspnea, exercise capacity, degree of hyperinflation, and comorbidity, whereas in women the only significant predictors were dyspnea and oxygenation. The regression model for men explained $87 \%$ of the variation in SGRQ scores but only $47 \%$ for women. Thus, in women, factors not assessed in the model may be influencing their quality of life.

The experience of dyspnea has physical, affective, and cognitive dimensions. The impact of dyspnea on patient functioning is influenced not only by the degree of lung dysfunction but also by the patient's emotional response to and higher order interpretation of the sensation (e.g., the meaning attached). For example, limitations in exercise performance in patients with COPD are more strongly associated with the degree of emotional distress caused by dyspnea than by the intensity of the dyspneic sensation (2). Neurobiologic studies demonstrate that women have a higher intrinsic sensitivity to noxious somatic sensations, including dyspnea (25). Neuroimaging studies also demonstrate gender differences in the laterality of prefrontal cortical processing of noxious stimuli (30). Because this region is involved in the cognitive modulation of emotion, it may be responsible for differences in the affective associations with dyspnea for women. Women also show greater attention to and awareness of somatic sensations than do men, making it more likely that dyspneic sensations will be detected (31).

Women with COPD also demonstrate higher levels of anxiety and depression and worse symptom-related quality of life than their male counterparts (32). Anxiety and depression also appear to be particularly pronounced in patients with COPD requiring hospitalization. Risk of rehospitalization for patients with COPD is increased for patients with anxiety and low health status (33). Two studies of hospitalized patients with COPD recorded significantly higher anxiety scores in women than men $(34,35)$. What is not clear, however, is whether the depression is a result of or a contributor to the risk of rehospitalization.

\section{GENDER DIFFERENCES IN COPD BIOLOGY AND PHYSIOLOGY}

Clinical data would suggest that sex hormones affect airway function (25). Incidence rates for asthma are lower in girls than boys up to age 15 . After that, incidence rates in women are higher until the perimenopausal period (25). Premenstrual aggravation of symptoms has been noted in up to $40 \%$ of female patients with asthma (25). A prospective cohort study that evaluated the association between postmenopausal hormone use and new diagnoses of asthma or COPD reported increased risk of asthma compared with non-hormone users but no difference in incidence of newly diagnosed COPD (36). Thus, although sex hormones appear to influence airway function in asthma, whether they contribute to COPD pathogenesis remains unclear. No prospective data exist on estrogen replacement and pulmonary function in COPD, an important topic for future study.

From a physiologic perspective, an analysis of emphysematous patients from the National Emphysema Trial (NETT) reported that men were significantly more likely than women to demonstrate reversibility of airway obstruction (37). In contrast, analyses from the Lung Health Study in a patient population with milder disease did not suggest differences between the genders in bronchodilator response (38). Hence, the relationship between gender and bronchoreversibility in COPD may also be complicated by the degree and severity of emphysema and airway disease.

Recently, additional data from the NETT showed that, on radiologic analysis, women demonstrated less severe overall emphysema, particularly in the periphery of the lung (2). Histologic examination revealed that bronchioles in female patients had significantly thicker airway walls (epithelium and adventitial components) and smaller lumens. These results suggest that men and women may respond differently in the type and location of lung damage due to tobacco exposure. It is interesting to note that chronic bronchitis is more prevalent in women, whereas emphysema is more prevalent in men. Gender dimorphism in COPD was first suggested by Burrows and colleagues in 1987 (39). They suggested that there were two primary types of COPD: chronic asthmatic bronchitis and emphysema. In a group of patients they studied, those with chronic asthmatic bronchitis were more frequently female, experienced less rapid decline in pulmonary function, and had lower mortality. The emphysematous group was primarily male and experienced more rapid decline in lung function and higher mortality. These phenotypic tendencies, if real, could potentially have important therapeutic implications.

COPD is increasingly recognized to be a chronic inflammatory disease (40) associated with progressive infiltration of the lungs by innate and adaptive inflammatory leukocytes, even after smoking cessation. The increased responsiveness of the female immune system may be a factor in female predominance of chronic bronchitics. Moreover, emphysema may be an autoimmune disease $(41,42)$. It has been reported that the serum of some patients with end-stage emphysema contains anti-endothelial cell antibodies (42), but whether such antibodies induce or result from the lung destruction is currently uncertain. Women also predominate the 5 to $12 \%$ of patients with COPD who are nonsmokers. In one such case series, organ-specific autoimmune disease was 
present in $32 \%$ of patients (43). The autoimmune hypothesis of COPD is intriguing because most diseases conventionally considered to be autoimmune are more prevalent in women than in men and this represents an area for possible future research.

\section{THERAPEUTIC IMPLICATIONS}

Smoking cessation is clearly the most effective intervention for patients with COPD. The Lung Health Study demonstrated that women who became sustained quitters had an average improvement in $\mathrm{FEV}_{1} \%$ predicted during the first year that was 2.5 times greater than the improvement in males (44). Reporting on longitudinal associations among smoking (cessation), lung function, and symptoms in patients with COPD, Watson and colleagues showed that an increase in the number of cigarettes smoked heightened the risk of developing wheeze and phlegm in men, but not in women (16). Conversely, remission of symptoms was more likely in men with a reduction in numbers of cigarettes smoked. Thus, smoking cessation appears to benefit women more in terms of lung function, but less with respect to symptoms. The symptomatic benefit to men may partially explain why women have greater difficulty in sustaining long-term abstinence from tobacco than men (4). Nicotine replacement therapy has been shown to reduce cravings less effectively for women than men, resulting in more weight gain in women (45). In 2001, the U.S. Surgeon General concluded that across all treatments women have more difficulty giving up smoking than men, both at shortterm and long-term follow-up (46). Women, however, may still significantly benefit from smoking cessation therapies. Buproprion is equally effective in females and males with COPD (47). Similar findings have been reported with the novel $\alpha 4 \beta 2$ nicotinic acetylcholine receptor partial agonist/antagonist varenicline (48).

\section{TABLE 1. FUTURE DIRECTIONS OF RESEARCH FOR GENDER DIFFERENCES IN CHRONIC OBSTRUCTIVE PULMONARY DISEASE}

- Women have greater difficulty sustaining tobacco abstinence (46).

- Women may exhibit greater loss of lung function than men (Table E1).

- Sustained female quitters exhibit 2.5 times greater $\mathrm{FEV}_{1} \%$ predicted improvement than men (44). obacco Use/Susceptibility

- Optimally designed longitudinal studies are required to better define if women are more susceptible to loss of lung function secondary to tobacco smoke.

- More effective smoking cessation therapies and programs targeted to women need to be developed and prospectively tested.
- The effect of sex hormones on airway function is not clear (25). Sex hormones appear to influence airway function in asthma, but contribution to COPD pathogenesis remains unclear (36).

- There is a predominance of women among COPD patients who are nonsmokers (43).

- NHIS data suggest that chronic bronchitis is more common in women and emphysema more common in men (8).

- Data from the NETT demonstrated distribution and severity of emphysema differs between men and women (37); women with emphysema were less likely to display reversibility of airway obstruction (2)

- In a general COPD population, the probability of respiratory deterioration when stopping inhaled steroids has been suggested to be higher in women than men (50).

- In patients with asthma, the plasma albuterol concentration at which maximal bronchodilation is observed was nearly twice as great in men as compared with women (51).
Biologic/Phenotypic Differences

- No prospective data exist on estrogen replacement and pulmonary function in COPD. Future clinical trials in COPD should obtain data regarding factors associated with sex hormone exposure, including parity and history of oral contraceptive and hormone replacement use.

- Better epidemiologic and mechanistic studies are required to better understand the immunologic and hormonal determinants of fixed airway obstruction in nonsmokers and how these relate to gender.

- Better phenotypic characterization of COPD in men and women is required.

- Well-designed studies assessing gender physiologic differences are required. This includes assessment of bronchoreversibility.

- Detailed imaging studies in well-defined, large populations are required to define if gender differences exist in the manifestation of airway disease versus emphysema.

- Data examining the potential relationship between COPD phenotype and response to therapy are required.

- Studies that address if phenotypic differences between the genders are related to different genetic or epigenetic profiles should be performed.

- Difference in comorbidity between the genders should be addressed. This includes differences in osteoporosis and cardiovascular disease among many others.

- Investigation is required to define if autoimmunity is a more common phenomenon in women with COPD.

- Animal models may provide a better understanding of the relationship between tobacco, sex hormones, and airway obstruction/emphysema.
- Dyspnea and HRQOL are more impaired in women than men for similar degree of physiologic impairment $(28,29)$.

- Higher prevalence of anxiety in women with COPD (33-35).
Symptoms/Quality of Life

- A better understanding is required to define gender-related determinants of dyspnea and HRQOL in COPD.

- The determinants of anxiety and depression in COPD patients as a function of gender need to better defined.

- The impact of these differences on the risk of hospitalization and measures of disease progression needs additional study.

- The impact of treatment of anxiety and depression in COPD on the risk of hospitalization and other long-term outcomes should be explored.

Therapeutic Implications

- Therapeutic trials in COPD have not adequately recruited women.

- An improved understanding of differential treatment responses between the genders will require that trials are adequately powered for such analyses.

- Survival is better in women on LTOT (53)

- Survival is worse in women on LTOT (54). defined in future prospective studies.

Definition of abbreviations: COPD = chronic obstructive pulmonary disease; HRQOL= health-related quality of life; LTOT = long-term home oxygen therapy; NETT = National Emphysema Trial; NHIS = National Health Interview Survey. 
Little is known about gender differences with respect to response to standard pharmacologic therapies in COPD because studies generally have not been designed to assess the impact of treatment stratified by sex. Future COPD research must increase the number of women included in therapeutic trials to allow adequate power to examine sex-stratified analyses. Because COPD is increasingly becoming a disease of women, many studies are being conducted that are underpowered to detect gender treatment differences. Regression analysis of data from the Euroscop study suggested that inhaled steroid use was a significant predictor of reduced phlegm production in men but not women (16). These results are compatible with findings in asthma (49) where multiple linear regression analysis showed that the magnitude of the steroid effect (decreased airway responsiveness to methacholine) over 6 weeks was significantly greater in males than females.

The probability of respiratory deterioration (either symptomatic or exacerbation) when stopping inhaled steroids has been suggested to be higher in women than men with COPD (hazard ratio [HR], 2.14; 95\% CI, 1.02-1.08) (50). In patients with asthma, the plasma albuterol concentration at which maximal bronchodilation is observed was nearly twice as great in men as compared with women (median 6.4 vs. $3.3 \mathrm{ng} / \mathrm{ml}$ ), suggesting that women are more sensitive to albuterol in their $\mathrm{FEV}_{1}$ response (51). Yet, in emphysematous patients, NETT data demonstrated that men were significantly more likely than women to demonstrate reversibility of airway obstruction (37). This issue needs to be further investigated with prospective studies.

Long-term home oxygen therapy (LTOT) improves survival in COPD. A Japanese study of patients treated with LTOT for COPD, tuberculosis sequelae, or interstitial pneumonia showed significantly better survival in women, despite a higher average baseline $\mathrm{Pa}_{\mathrm{CO}_{2}}$ (see Figure E1) (52). This finding was confirmed in a meta-analysis of LTOT in which a survival advantage also existed for women (53). However, Machado and coworkers reported in patients with COPD receiving LTOT that survival was significantly worse in females, those with lower body mass index, and lower $\mathrm{Pa}_{\mathrm{O}_{2}}$ (54). The study did not stratify the analyses by sex; thus, it is not clear if the mentioned risk factors were determined by male or female sex. Discrepancies between studies may be due to patient population and analytical approaches, the criteria for defining COPD (e.g., GOLD [Global Initiative for Chronic Obstructive Lung Disease] vs. BTS [British Thoracic Society]), and the rules for indications to start LTOT. More studies that include analysis stratified by gender or adding an interaction term with gender are clearly needed to determine whether women have lesser or greater benefit from oxygen therapy, and if so, whether this difference is confounded by smoking and other treatments.

\section{FUTURE DIRECTIONS}

It is evident that gender differences in disease impact, expression, progression, and response to therapy have been noted in COPD. On the other hand, investigations targeting genderrelated differences are in their infancy. Focused investigation in this arena is clearly warranted. Some areas that should be considered are enumerated in Table 1.

Conflict of Interest Statement: M.K.H. does not have a financial relationship with a commercial entity that has an interest in the subject of this manuscript. D.P. does not have a financial relationship with a commercial entity that has an interest in the subject of this manuscript. D.M.M. serves on advisory boards for Boehringer Ingelheim (BI), Pfizer, GlaxoSmithKline (GSK), and Ortho Biotech; is on the speakers' bureau for BI, Pfizer, GSK, and Dey; and has received research grants from GSK, Novartis, and Pfizer. N.D.G. does not have a financial relationship with a commercial entity that has an interest in the subject of this manuscript. S.B. has served on advisory boards for GSK, Altana, Schering Plough,
Merck, Novartis, Pfizer, and Sepracor; has participated in COPD workshops funded by AstraZeneca and GSK: and is Scientific Director for the Burden of Obstructive Lung Disease (BOLD) initiative, which receives funding from Pfizer, $\mathrm{BI}$, AstraZeneca, Altana, Novartis, Merck, Chiesi, Schering Plough, and Sepracor. J.L.C. has been reimbursed by Sepracor for attending a conference and received $\$ 3,000$ in speaker's fees, and is an investigator in an ongoing multicenter clinical trial sponsored by BI. F.J.M is a consultant for Altana Pharma and has received compensation greater than $\$ 10 \mathrm{~K}$. F.J.M. has been a member of several advisory boards, CME committees, and the speaker's bureau for BI, Pfizer, and GSK. His total compensation per company is greater than $\$ 10 \mathrm{~K}$. In addition, F.J.M. is on an advisory board for Novartis and speaker's bureaus for Sepracor and Astra, receiving less than $\$ 10 \mathrm{~K}$ per company. F.J.M. has been an investigator for industry-sponsored studies for GSK, BI, and Actelion.

\section{References}

1. Mannino D, Homa D, Akinbami L, Ford E, Redd S. Chronic obstructive pulmonary disease surveillance: United States, 1971-2000. MMWR Surveill Summ 2002;51:1-16.

2. Martinez F, Curtis J, Sciurba F, Mumford J, Giardino N, Weinmann G, Kazerooni E, Murray S, Criner G, Sin D, et al.; NETT Research Group. Sex differences in severe pulmonary emphysema. Am J Respir Crit Care Med 2007;176:243-252.

3. National Center for Health Statistics. Deaths: final data for 1999. Hyattsville, MD: U.S. Department of Health and Human Services, Centers for Disease Control and Prevention. National Vital Statistics Report 2001;49:1-116.

4. Varkey AB. Chronic obstructive pulmonary disease in women: exploring gender differences. Curr Opin Pulm Med 2004;10:98-103.

5. Halbert RJ, Natoli JL, Gano A, Badamgarav E, Buist AS, Mannino DM. Global burden of COPD: systematic review and meta-analysis. Eur Respir J 2006;28:523-532.

6. Menezes AM, Perez-Padilla R, Jardim JR, Muino A, Lopez MV, Valdivia G, Montes de Oca M, Talamo C, Hallal PC, Victora CG. Chronic obstructive pulmonary disease in five Latin American cities (the PLATINO study): a prevalence study. Lancet 2005;366:1875-1881.

7. Schirnhofer L, Lamprecht B, Vollmer WM, Allison MJ, Studnicka M, Jensen RL, Buist AS. COPD prevalence in Salzburg, Austria: results from the Burden of Obstructive Lung Disease (BOLD) study. Chest 2007;131:29-36.

8. American Lung Association Epidemiology and Statistics Unit, Research and Program Services. Trends in chronic bronchitis and emphysema: morbidity and mortality [Internet]. New York: American Lung Association; 2007 Sep [accessed 2007 Nov 7]. 29 p. Available from: http:// www.lungusa.org (click on Research tab, then Data \& Statistics tab).

9. Macintyre S, Hunt K, Sweeting H. Gender differences in health: are things really as simple as they seem? Soc Sci Med 1996;42:617-624.

10. Lacasse Y, Brooks D, Goldstein RS. Trends in the epidemiology of COPD in Canada, 1980 to 1995. COPD and Rehabilitation Committee of the Canadian Thoracic Society. Chest 1999;116:306-313.

11. Canadian Institute for Health Information; Canadian Lung Association; Health Canada; Statistics Canada. Respiratory disease in Canada [Internet] [accessed March 9, 2007]. Available from: http:/www.phacaspc.gc.ca/publicat/rdc-mrc01/pdf/rdc0901e.pdf

12. Chapman K, Tashkin D, Pye D. Gender bias in the diagnosis of COPD. Chest 2001;119:1691-1695.

13. Miravitlles M, de la Roza C, Naberan K, Lamban M, Gobartt E, Martin A, Chapman KR. Attitudes toward the diagnosis of chronic obstructive pulmonary disease in primary care. Arch Bronconeumol 2006;42:3-8. Spanish.

14. Kesten S, Chapman K. Physician perceptions and management of COPD. Chest 1993;104:254-258.

15. Franks P, Clancy CM, Naumburg EH. Sex, access, and excess. Ann Intern Med 1995;123:548-550.

16. Watson L, Vestbo J, Postma D, Decramer M, Rennard S, Kiri V, Vermeire P, Soriano J. Gender differences in the management and experiences of chronic obstructive pulmonary disease. Respir Med 2004;98:1207-1213.

17. Chapman K. Chronic obstructive pulmonary disease: are women more susceptible than men? Clin Chest Med 2004;25:331-341.

18. Doll R, Peto R. Mortality in relation to smoking: 20 years' observations on male British doctors. BMJ 1976;2:1525-1536.

19. Doll R, Gray R, Hafner B, Peto R. Mortality in relation to smoking: 22 years' observations on female British doctors. BMJ 1980;280:967971.

20. Gan WQ, Man SF, Postma DS, Camp P, Sin DD. Female smokers beyond the perimenopausal period are at increased risk of chronic 
obstructive pulmonary disease: a systematic review and meta-analysis. Respir Res 2006;7:52.

21. Watson L, Vonk JM, Lofdahl CG, Pride NB, Pauwels RA, Laitinen LA, Schouten JP, Postma DS. Predictors of lung function and its decline in mild to moderate COPD in association with gender: results from the Euroscop study. Respir Med 2006;100:746-753.

22. Connett J, Murray R, Buist A, Wise R, Bailey W, Lindgren P, Owens G; Lung Health Study Research Group. Changes in smoking status affect women more than men: results of the Lung Health Study. Am J Epidemiol 2003;152:973-979.

23. Silverman E, Weiss S, Drazen J, Chapman H, Carey V, Campbell E, Denish P, Silverman R, Celedon J, Reilly J, et al. Gender-related differences in severe, early-onset chronic obstructive pulmonary disease. Am J Respir Crit Care Med 2000;162:2152-2158.

24. Patrick DL, Cheadle A, Thompson DC, Diehr P, Koepsell T, Kinne S. The validity of self-reported smoking: a review and meta-analysis. $\mathrm{Am}$ J Public Health 1994;84:1086-1093.

25. Becklake MR, Kauffmann F. Gender differences in airway behaviour over the human life span. Thorax 1999;54:1119-1138.

26. Mannino DM, Holguin F, Greves HM, Savage-Brown A, Stock AL, Jones RL. Urinary cadmium levels predict lower lung function in current and former smokers: data from the Third National Health and Nutrition Examination Survey. Thorax 2004;59:194-198.

27. Ben-Zaken Cohen S, Paré P, Man S, Sin D. The growing burden of chronic obstructive pulmonary disease and lung cancer in women: examining sex differences in cigarette smoke metabolism. Am $J$ Respir Crit Care Med 2007;176:113-120.

28. de Torres JP, Casanova C, Hernandez C, Abreu J, Aguirre-Jaime A, Celli BR. Gender and COPD in patients attending a pulmonary clinic. Chest 2005;128:2012-2016.

29. de Torres Tajes JP, Casanova C, Hernandez C, Abreu J, Montejo de Garcini A, Aguirre-Jaime A, Celli BR. Gender associated differences in determinants of quality of life in patients with COPD: a case series study. Health Qual Life Outcomes 2006;4:72.

30. Paulson PE, Minoshima S, Morrow TJ, Casey KL. Gender differences in pain perception and patterns of cerebral activation during noxious heat stimulation in humans. Pain 1998;76:223-229.

31. Shields SA, Simon A. Is awareness of bodily change in emotion related to awareness of other bodily processes? J Pers Assess 1991;57:96-109.

32. Di Marco F, Verga M, Reggente M, Maria Casanova F, Santus P, Blasi F, Allegra L, Centanni S. Anxiety and depression in COPD patients: the roles of gender and disease severity. Respir Med 2006;100:1767-1774.

33. Gudmundsson G, Gislason T, Janson C, Lindberg E, Hallin R, Ulrik CS, Brondum E, Nieminen MM, Aine T, Bakke P. Risk factors for rehospitalisation in COPD: role of health status, anxiety and depression. Eur Respir J 2005;26:414-419.

34. Dowson C, Laing R, Barraclough R, Town I, Mulder R, Norris K, Drennan C. The use of the Hospital Anxiety and Depression Scale (HADS) in patients with chronic obstructive pulmonary disease: a pilot study. $N$ Z Med $J$ 2001;114:447-449.

35. Gudmundsson G, Gislason T, Janson C, Lindberg E, Suppli Ulrik C, Brondum E, Nieminen MM, Aine T, Hallin R, Bakke P. Depression, anxiety and health status after hospitalisation for COPD: a multicentre study in the Nordic countries. Respir Med 2006;100:87-93.

36. Barr RG, Wentowski CC, Grodstein F, Somers SC, Stampfer MJ, Schwartz J, Speizer FE, Camargo CA Jr. Prospective study of postmenopausal hormone use and newly diagnosed asthma and chronic obstructive pulmonary disease. Arch Intern Med 2004;164:379-386.

37. Martinez FJ, Criner G, Hoffman E, Wise RA, Gay S, Flaherty K, Make B, Sciurba F. Spirometric bronchoreversibility (SBR) in emphysema patients. Proc Am Thorac Soc 2005;1:A635.

38. Anthonisen NR, Lindgren PG, Tashkin DP, Kanner RE, Scanlon PD, Connett JE. Bronchodilator response in the lung health study over 11 yrs. Eur Respir J 2005;26:45-51.
39. Burrows B, Boom J, Traver G, Cline M. The course and prognosis of different forms of chronic airways obstruction in a sample from the general population. $N$ Engl J Med 1987;317:1209-1214.

40. Curtis JL, Freeman CM, Hogg JC. The immunopathogenesis of COPD: insights from recent research. Proc Am Thorac Soc 2007;4: $512-521$.

41. van der Strate BW, Postma DS, Brandsma CA, Melgert BN, Luinge MA, Geerlings M, Hylkema MN, van den Berg A, Timens W, Kerstjens HA. Cigarette smoke-induced emphysema: a role for the B cell? Am J Respir Crit Care Med 2006;173:751-758.

42. Taraseviciene-Stewart L, Douglas IS, Nana-Sinkam PS, Lee JD, Tuder RM, Nicolls MR, Voelkel NF. Is alveolar destruction and emphysema in chronic obstructive pulmonary disease an immune disease? Proc Am Thorac Soc 2006;3:687-690.

43. Birring S, Brightling C, Bradding P, Entwisle J, Vara D, Grigg J, Wardlaw A, Pavord I. Clinical, radiologic, and induced sputum features of chronic obstructive pulmonary disease in nonsmokers: a descriptive study. Am J Respir Crit Care Med 2002;166:10781083.

44. Scanlon PD, Connett JE, Waller LA, Altose MD, Bailey WC, Buist AS Smoking cessation and lung function in mild-to-moderate chronic obstructive pulmonary disease. The Lung Health Study. Am J Respir Crit Care Med 2000;161:381-390.

45. Nusbaum ML, Gordon M, Nusbaum D, McCarthy MA, Vasilakis D. Smoke alarm: a review of the clinical impact of smoking on women. Prim Care Update Ob Gyns 2000;7:207-214.

46. U.S. Surgeon General. Women and smoking: a report of the Surgeon General-2001 [Internet] [accessed March 9, 2007]. Available from: http://www.cdc.gov/tobacco/data_statistics/sgr/sgr_2001/index.htm

47. Tashkin D, Kanner R, Bailey W, Buist S, Anderson P, Nides M, Gonzales D, Dozier G, Patel MK, Jamerson B. Smoking cessation in patients with chronic obstructive pulmonary disease: a doubleblind, placebo-controlled, randomised trial. Lancet 2001;357:15711575 .

48. Gonzales D, Rennard SI, Nides M, Oncken C, Azoulay S, Billing CB, Watsky EJ, Gong J, Williams KE, Reeves KR. Varenicline, an alpha4beta2 nicotinic acetylcholine receptor partial agonist, vs sustained-release bupropion and placebo for smoking cessation: a randomized controlled trial. JAMA 2006;296:47-55.

49. Convery RP, Leitch DN, Bromly C, Ward RJ, Bartlett G, Hendrick DJ. Effect of inhaled fluticasone propionate on airway responsiveness in treatment-naive individuals: a lesser benefit in females. Eur Respir J 2000;15:19-24.

50. Schermer TR, Hendriks AJ, Chavannes NH, Dekhuijzen PN, Wouters EF, van den Hoogen H, van Schayck CP, van Weel C. Probability and determinants of relapse after discontinuation of inhaled corticosteroids in patients with COPD treated in general practice. Prim Care Respir J 2004:13:48-55.

51. Lima JJ, Mohamed MH, Self TH, Eberle LV, Johnson JA. Importance of beta(2)adrenergic receptor genotype, gender and race on albuterol-evoked bronchodilation in asthmatics. Pulm Pharmacol Ther 2000;13:127-134.

52. Miyamoto K, Aida A, Nishimura M, Aiba M, Kira S, Kawakami Y. Gender effect on prognosis of patients receiving long-term home oxygen therapy. The Respiratory Failure Research Group in Japan. Am J Respir Crit Care Med 1995;152:972-976.

53. Crockett AJ, Cranston JM, Moss JR, Alpers JH. Survival on long-term oxygen therapy in chronic airflow limitation: from evidence to outcomes in the routine clinical setting. Intern Med $J$ 2001;31:448454.

54. Machado MC, Krishnan JA, Buist SA, Bilderback AL, Fazolo GP, Santarosa MG, Queiroga F Jr, Vollmer WM. Sex differences in survival of oxygen-dependent patients with chronic obstructive pulmonary disease. Am J Respir Crit Care Med 2006;174:524-529. 